\title{
Julian Bream (1933-2020)
}

\author{
Fabio Zanon
}

\author{
Royal Academy of Music (ENG) | Brasil
}

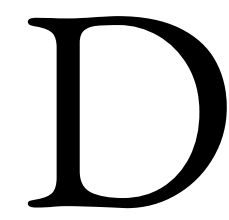
esde o dia 14 de agosto de 2020 violonistas e aficionados da música no mundo todo têm lamentado a morte de Julian Bream. Junto-me à legião de violonistas prof issionais que relembram a primeira vez em que o ouviram, pelo rádio, ainda crianças, por acaso: o efeito foi sinestésico, arrebatador, um banquete para os sentidos. Ali, percebi um propósito musical profundamente culto e senti, pela primeira vez, que toda uma gama de expressão poderia caber apenas em um violão. Foi-me dada de presente a ideia do tipo de músico que eu deveria me esforçar por me tornar. Outros artistas tinham o poder de trazer os ouvintes ao violão, mas Julian conseguia trazernos a uma paisagem musical e cultural mais ampla através de seu violão e de seu alaúde.

O método Iniciação ao Violão, de Henrique Pinto, do qual me servi para dar os primeiros passos como violonista, traz em seu prefácio uma comparação das personalidades contrastantes de Andrés Segovia e Bream: o primeiro um personalista incandescente, um músico para os sentidos que tornava cada música sua; o segundo um sofisticado estudioso que se esforçava para encontrar os matizes apropriados para cada momento e cada compositor, em leituras rigorosas. Pela perspectiva de hoje, pode-se notar que as linhas de continuidade entre eles são tão nítidas quanto os elementos de ruptura que os separam: ouvimos a arte de Julian Bream como uma síntese em que "o caos deve brilhar através do adorno da ordem", tomando emprestadas as palavras de Novalis. O que é mais desconcertante nesse paralelo, entretanto, é o rumo improvável dos acontecimentos que levaram o menino da classe trabalhadora dos subúrbios de Londres até o que agora vemos como o maior ponto de inflexão na história do violão na segunda metade do século XX: o artista que, através de uma formação musical impecável, conhecimento histórico e uma concepção finamente regulada daquilo que o violão era 
capaz de transmitir - mas ainda não havia transmitido - trouxe-o, com êxito inegável, a uma nova plataforma de fruição estética, profundidade de argumento musical e respeitabilidade intelectual.

\section{I}

Nascido em 15 de julho de 1933, no bairro de Battersea, no sul de Londres, a poucas quadras da icônica estação de energia elétrica que define a paisagem daquela área, ele cresceu um pouco mais longe, em Hampton, onde sua avó tinha um pub. Talvez a proximidade do antigo palácio real de Hampton Court possa justificar seu interesse, mais tarde, pela música renascentista. Seu precoce - e perene - amor pelo jazz clássico de Django Reinhardt encontrou um rival quando seu pai trouxe para casa um disco de Segovia tocando Recuerdos de la Alhambra. Julian descrevia esse encontro da forma mais deslumbrada e afetuosa - seu fascínio pela qualidade do som, uma experiência auditiva completamente nova para ele, e que o atraiu para o violão clássico.

Arrasada pelo divórcio de seus pais, sua saúde emocional ficou ainda mais abalada quando sua mãe se foi embora, deixando ao marido o encargo de cuidar dos filhos. Isso criou uma proximidade ainda maior com seu pai, que não poupou esforços para encontrar ensino adequado para o garoto que, muito embora não fosse um estudante lá muito esforçado, mostrava-se extremamente rápido no aprendizado do violão.

$\mathrm{Na}$ Inglaterra do pós-guerra havia uma ideia generalizada de que violão clássico era território exclusivamente espanhol e de que não havia muita afinidade entre os britânicos e aquele instrumento latino. Ainda assim, havia uma Sociedade Filarmônica de Violonistas; lá, seu pai conheceu o Dr. Boris Perott, um médico e violonista amador nascido na Rússia. Perott tornou-se o único professor que Julian teve, que o estimulou a tocar com o dedo mínimo apoiado sobre o tampo e a usar instrumentos com mais de seis cordas para parecer diferente. Nessa situação, não estaria longe da verdade dizer que Bream foi, em larga escala, um autodidata; isso acabou por forçá-lo a desenvolver um inusitado grau de autonomia como músico. Apesar das ideias algo bizarras de Perott, seu ensino parece ter sido eficiente o bastante para que Julian desse seu primeiro recital profissional em Cheltenham aos treze anos. A boa receptividade levou a uma sucessão de convites para tocar ao redor do país.

No mesmo ano auspicioso de 1947, ele assistiu ao primeiro concerto de Segovia em Londres depois da Guerra, com um par de binóculos para analisar sua técnica de produção de som. Ele assim 
descreveu a ocasião, numa entrevista para o rádio: "eu fiquei simplesmente fascinado por ele. Nunca tinha ouvido uma articulação tão bonita, tanta variedade de cores e uma interpretação tão maravilhosamente integrada”.

Ele foi apresentado a Segovia naquela ocasião. O sentimento geral de que ele deveria se tornar um protégé de Segovia foi frustrado; eles se encontraram algumas vezes, em situações algo embaraçosas, e Segovia se ofereceu para levá-lo como uma espécie de aprendiz em suas turnês. Apesar dos esforços comunitários para arrecadar fundos para essa empreitada, seu pai não a considerou vantajosa e recusou o convite. Isso azedou sua relação com Segovia para sempre, o que não suficiente para diminuir sua irrestrita admiração pelo mito.

Bream foi aceito para estudar no Royal College of Music em 1949, com uma bolsa integral como aluno de piano e composição. Por mais prosaico que isso possa parecer, ele foi, de fato, um dos primeiros - se não o primeiro - violonistas de renome que receberam uma formação completa de conservatório (o curso de violão daquela instituição só seria criado dez anos mais tarde). O diretor do Royal College, Sir George Dyson, tinha simpatia por seu talento musical, mas não pelo violão. Ele também aconselhou o jovem a "limpar" seu sotaque suburbano para aumentar suas chances de aceitação social.

Em 1950 seu pai morreu, e Julian, com apenas 17 anos, se viu obrigado a ganhar a vida sem uma rede de segurança. Nessa época ele conheceu Thomas Goff, um advogado que, nas horas vagas, construía alaúdes e cravos. Goff foi de importância crucial para a vida artística do jovem Bream. Ele não só o persuadiu a aprender a tocar alaúde - algo que, novamente, ele fez por conta própria - e a mergulhar no assombroso repertório renascentista que ainda estava adormecido nos arquivos dos museus, mas também construiu o alaúde que ele usaria por uma década, a princípio em transmissóes radiofônicas e mais tarde também em gravações. Goff também organizou, em 1951, seu primeiro recital em um teatro de prestígio, o Wigmore Hall, que se tornaria o ponto de partida para sua carreira internacional.

Em 1952, Bream foi convocado a prestar três anos de serviço militar. Ele tocou guitarra e violoncelo em bandas militares, mas conseguiu também burlar as regras e morar fora do quartel, dando continuidade à sua carreira. Nessa época, começou a se apresentar como solista de orquestra e encontrou, pela primeira vez, o compositor Benjamin Britten e seu parceiro, o notável tenor Peter Pears, numa amizade que culminou numa sequência de recitais de canções renascentistas. Antes do 
final de 1954 ele já havia se apresentado no Wigmore Hall várias vezes e adotado o formato de recital com alaúde na primeira parte e violão na segunda, com aclamação da crítica.

Em 1955 ele foi dispensado das forças armadas; isso permitiu que ele tocasse no exterior pela primeira vez; concertos de maior visibilidade e prestígio começaram a se tornar rotina. Nessa altura, os pilares de suas conquistas artísticas começaram a se tornar aparentes. Seus recitais começaram a incluir obras escritas expressamente a seu pedido; no final dos anos 1950 estreou obras do porte da Sonatina de Lennox Berkeley, Kammermusik 1958 de Hans Werner Henze e o Concerto para violão e orquestra de Malcolm Arnold. Ao mesmo tempo, encontrou o equilíbrio entre o alaúde e o violão e entre atividade como solista e camerista - áreas que não tinham sido exploradas por Segovia. A carreira discográfica começou em 1955, primeiramente acompanhando Peter Pears em cançôes de alaúde, e logo em seguida como solista, no selo Westminster. Rapidamente ele fugiu do modelo então corrente de álbuns em forma de coletânea de peças curtas; em 1957 gravou um álbum todo dedicado a Bach, ao violão, e outro, todo de Dowland, com o alaúde.

No início dos anos ' 60 sua fama começou a se espalhar internacionalmente; tornou-se um artista favorito na Inglaterra, convidado cativo dos maiores festivais e de programas de televisão. Em 1961, criou o Julian Bream Consort, especializado em música elisabetana, um dos primeiros grupos estabelecidos para a prática de interpretação historicamente informada. Em 1964, aos 30 anos, Bream estreou o Nocturnal, op. 70, de Benjamin Britten, uma obra que redefiniu a orientação estética e as capacidades expressivas do violão. Um dia depois, recebeu reconhecimento oficial com a Ordem do Império Britânico (OBE).

Um novo contrato de gravações, desta feita com a RCA, em 1959, duraria trinta anos. Isso iniciou uma sucessão de discos agora emblemáticos, com destaque para 20th Century Guitar, em 1966, um divisor de águas na indústria discográfica. Nesse estágio, ficou claro que sua voz artística era persuasiva o bastante para promover música contemporânea entre ouvintes que, de outra forma, a rejeitariam, e, ao mesmo tempo, introduzir o violão a ouvintes que, em outras mãos, não teriam interesse por ele.

Estabelecendo residência numa propriedade rural nos anos 70, começou também uma colaboração com construtores de instrumentos, numa oficina montada no antigo celeiro. Dois dos luthiers mais destacados do pós-guerra, David Rubio e José Romanillos, ali começaram sua carreira, assim como outros fabricantes de alaúdes e cravos. 
Nessa época, tornou-se reconhecido como uma força dentro do cenário cultural. Seu nome era mencionado em obras literárias e artigos jornalísticos; possuir um álbum de Julian Bream era, para aqueles com apreço pela cultura, tão obrigatório quanto visitar uma exposição de um artista famoso, assistir a uma peça de Harold Pinter ou ler um livro vencedor do Booker Prize.

Manteve uma agenda intensa de concertos até 2001. Foram décadas que presenciaram um fluxo constante de projetos de toda sorte: estreias mundiais, programas de TV, concertos em duo com John Williams e George Malcolm, recitais de poesia com a atriz Peggy Ashcroft, e gravações de concertos para violão e orquestra com maestros do quilate de Colin Davies, Simon Rattle ou André Previn. Ele recebeu a Medalha Villa-Lobos em 1977, um CBE (título de Comandante do Império Britânico) em 1985, e títulos de Doutor Honoris Causa das universidades de Surrey e Leeds. Entre 1979 e 1985 gravou uma coleção de álbuns de música espanhola, culminando em 1985 numa série televisiva em oito episódios, chamada ¡Guitarra!.

Toda essa atividade só foi interrompida temporariamente por um sério acidente automobilístico em 1984, em que esmagou o cotovelo direito numa colisão contra um pilar de viaduto. Felizmente recuperou-se rápido o suficiente para voltar aos palcos alguns meses mais tarde, com a técnica de mão direita ligeiramente alterada. A relação com a RCA terminou em 1989; seus últimos quatro álbuns foram lançados pela EMI, na década de 1990. Em 2001 celebrou o 50oㅡ aniversário de seu primeiro concerto no Wigmore Hall; este seria também seu concerto de despedida em Londres. O último concerto oficial se deu em Norwich, no dia 6 de maio de 2002. Caracteristicamente, estes últimos recitais incluíram uma quantidade de obras difíceis, que nunca havia tocado antes. Quando perguntado por que razão não preferiu continuar nos palcos por mais alguns anos, tocando programas menos exigentes, respondeu “esse não seria eu”.

Na década de 2010 estabeleceu o Julian Bream Trust, uma organização sem fins lucrativos que, num de seus braços, oferece bolsas de estudos a jovens estudantes excepcionalmente talentosos para que estudem nos conservatórios britânicos e, no outro, mantém a prática de encomendas de novas obras de compositores proeminentes. A estes estudantes tem sido conferido o encargo de estrear obras de Birtwistle, Julian Anderson, Brouwer, Olli Mustonen e Edward Cowie, sob sua supervisão.

Julian Bream pode partir na confiança de que seu legado se prolongará ainda por muitos anos, agora sob a direção de John Williams. 
Julian Bream foi um dos artistas emblemáticos da era das gravaçóes; ele percorreu toda a era do LP e, a partir de 1988, fez a transição para as gravações digitais. Seu prestígio lhe permitiu exercer total controle sobre o resultado artístico, gravando com instrumentos construídos na sua propriedade, usando como locação uma capela próxima (Wardour Chapel), sempre trabalhando com a mesma equipe técnica. Estes álbuns espalharam seu nome pelo mundo todo e, neste processo, ele investiu o violão com uma estatura artística insuspeita. Seu legado discográfico não só ajudou a estabelecer novas obras, mas também trouxe à ribalta obras de compositores como Giuliani e Diabelli, para não mencionar os compositores de alaúde e vihuela, que haviam sido negligenciados pela geração anterior de violonistas.

Sua personalidade intransigente cristalizou o método curatorial de escolha de repertório, o formato favorecido no final do século XX, exatamente o oposto das coletâneas sortidas então populares. Tanto em concertos quanto em gravaçóes, ele buscava um equilíbrio entre obras de substância e aquelas mais leves e coloridas, criando contraste e coesão estilística ao mesmo tempo. Dessa forma, o programa de um artista como ele, que se apresentava frequentemente nos teatros mais sisudos e em grandes festivais de música, não parecia deslocado quando posto ao lado de recitais de piano ou de grupos de câmara.

Suas gravações, em contraste com aquelas de uma geração anterior, exploravam cada área do repertório num escopo analítico. Álbuns como Dedication ou The Woods So Wild, por exemplo, são modelos de narrativa sem costuras aparentes, onde cada obra parece adicionar valor à obra seguinte.

Julian Bream será para sempre celebrado por seu esforço pela criação de um repertório de qualidade inquestionável e perene. Este desafio autoimposto começou bem cedo, já em 1947, quando estreou a Sonata de Terry Usher, e parece que será estendido para além da última obra que ele mesmo encomendou e revisou (Streams and Variations de Edward Cowie, de 2019). Seu repertório incluiu muita música à qual seu nome normalmente não é associado (por exemplo o Quinteto de Stephen Dodgson e o Concerto para Violão de Denis ApIvor). Ele sempre insistiu que não era o suficiente encomendar música nova, mas era preciso esperar pelo momento certo de fazê-lo e se jogar com alma para fazer com que a música funcionasse. Ele não tinha interesse por música chocante ou experimental, mas se empenhou por produzir um corpo de clássicos modernos. Ele não se esquivava 
de fazer uma turnê internacional com uma sonata atonal e densa de 30 minutos, tocando-a para qualquer tipo de plateia, se acreditasse que a obra valia o esforço. Dentre as duas dúzias de obras que ele de fato gravou e de muitas outras que estreou, podemos dizer com segurança que pelo menos uma dúzia de grandes obras têm seu lugar assegurado na história.

Considero seu legado gravado - tanto as gravações oficiais quanto aquelas feitas para o rádio ou pirateadas - uma fonte inesgotável de deleite e sabedoria musical. Uma escuta organizada e atenta revela que os ingredientes principais de seu sucesso foram uma qualidade avassaladora e uma nova visão interpretativa.

Enriquecido por sua experiência com o alaúde, Bream foi possivelmente o primeiro violonista de renome internacional a desenvolver um estilo polifônico de interpretação. Enquanto a geração mais velha, ainda que tocasse com um estilo convincente e belo, tendia a tratar até mesmo uma fuga de Bach como uma espécie de melodia acompanhada, Bream empregava um cuidado infinito no polimento de uma articulação coerente e na busca da proporção exata entre sentido horizontal e equilíbrio vertical. Em termos puramente técnicos ele talvez não fosse considerado imaculado pelos padróes atuais, mas até mesmo suas primeiras gravações demonstram uma preocupação em não permitir que as idiossincrasias do violão interfiram com valores musicais mais "salutares". Se uma nota tinha de ser sustentada em uma posição desconfortável em favor da continuidade da polifonia, se uma voz interna tinha de se destacar, se um legato amplo tinha de ser gerido, ele não poupava esforços para que isso acontecesse.

Seu tratamento do timbre, apesar de evidentemente influenciado por Segovia, obedece a uma abordagem mais analítica, pontuando ocorrências formais e ressaltando acontecimentos significativos na estrutura harmônica. Ao vivo, sua sonoridade era opulenta, sólida, meticulosa e envolvente, com baixos profundos e agudos brilhantes. Nos últimos anos não era totalmente imaculada, mas, quanto mais distante do palco estava o ouvinte, mais distinta se tornava. Muitos jovens violonistas consideram suas escolhas extremas de timbre repelentes ou desnecessárias. $\mathrm{O}$ que frequentemente se esquece é que ele empregava aqueles efeitos subordinados a uma visão estrutural cuidadosamente elaborada, que era, em última instância, sublinhada e revivificada por aquela superfície caleidoscópica. O mesmo pode ser dito por sua tendência a "empurrar" o fraseado com acentos em anacruses; novamente, essas eram decisóes conscientes de um estrategista para criar impulso e consciência polifônica, de uma forma similar àquela empregada por grandes artistas do 
piano como Horowitz e Schnabel.

Outro aspecto misterioso de sua arte era a urgência rítmica. Ele tinha um senso inexorável de pulso e periodicidade, dois fatores determinantes para produzir uma impressão superior de coesão; ainda assim, seu fraseado raramente se afigurava rígido.

Em resumo, ele não tocava apenas para outros violonistas; tocava para todos.

\section{III}

Numa profissão em que autoindulgência e apego pela imagem pública são tão presentes, poucas vezes encontrei um músico capaz de fazer uma avaliação tấo precisa e honesta da própria estatura, de suas forças e fraquezas. Há poucos músicos desse calibre que ousariam admitir, numa entrevista, a frustração por não ter tocado na estreia de Le Marteau Sans Maitre de Boulez, por saber que não daria conta de suas dificuldades rítmicas e de conjunto; ou que permitisse que seu constrangedor encontro com Stravinsky fosse incluído numa cinebiografia.

Ele era capaz de não se levar demasiadamente a sério. Certa feita fui cumprimenta-lo após um concerto e lá estava uma senhora que tentava mostrar-lhe um álbum de fotografias, dizendo que tinha uma foto dele junto com seu pai. Quando a foto finalmente foi encontrada, ficou evidente que não era Julian, mas John Williams com seu pai. Todos ao redor esperavam que ele fosse repreendê-la, mas, sorrindo por dentro, ele somente disse "estranho, não me lembro de usar óculos quando era criança; mas minha memória pode estar falhando". Todos foram embora completamente satisfeitos.

Para aqueles que tiveram a sorte de presenciar suas master classes como Professor Visitante da Royal Academy of Music, entre 1989 e 1995, ele tornou-se um modelo a ser seguido. Cada um de nós tem seu conjunto de memórias, sendo que as mais vívidas certamente contemplam sua imaginação musical e os altos e baixos de seu humor. Nunca dava instruções técnicas diretamente, no vazio, e nunca chamava um estudante pelo nome; técnica entrava na discussão uma vez que uma demanda musical se formulava. Quando toquei o Tema com Variaçốs de Berkeley para ele, pediu que eu imaginasse, na última variação, uma silhueta borrada pela neblina que gradualmente se torna mais nítida enquanto se aproxima. Não havia necessidade de uma instrução específica; essa imagem, por si, indiretamente construía a técnica necessária.

Ele podia ser abrasivo, quase cruelmente direto. Giacomo Susani, um de nossos últimos 
estudantes a trabalhar diretamente com ele, diz que ele não tinha filtros de consciência e seus comentários impiedosos podiam deixa-lo abatido, mas que aqueles encontros constituíram um desafio a encontrar sua própria verdade artística.

Uma vez um estudante da Alemanha tocou para ele o 2o movimento da 1a Sonata de Brouwer. A interpretação foi sensível, mas foi tocada no dobro do andamento que Bream normalmente escolhia. Eu fiquei aflito, esperando por uma repreensão ríspida, mas ele somente disse "tenho de admitir que tem pouco a ver com o que eu faço, mas ainda assim soa muito atraente”. A partir daí, ele conseguiu transformar a interpretação dizendo "tente fazer com que o violão soe como um piano antigo ouvido por acaso”.

Muito do sentimento de conclusão provocado por sua partida pode ser atribuído ao fato de que ele representava o violão da era analógica da segunda metade do século XX. Ele não estava nas mídias sociais, não tinha um celular e provavelmente sequer usava um endereço de e-mail. Sua carreira foi resoluta e estável, preparada para consumo lento e atento, construída passo a passo sobre uma base de reputação, reconhecimento dos pares e promoção de repertório denso. Mesmo sua sonoridade indecentemente sedutora e sua escolha de instrumentos indicavam, antes de mais nada, uma musicalidade construída para ser saboreada, ao vivo: tudo que se sustenta em um abrupto contraste com os padróes do século XXI, em que a personalidade artística e mesmo a técnica de produção de som têm de ser projetadas sob medida para consumo on-line.

Depois de seus últimos concertos lastimei o fato de que jamais ouviria aquela sonoridade mágica ao vivo novamente. Em 2020 eu choro a morte de um músico sem igual. Julian foi o violonista que gastei mais horas ouvindo, em toda minha vida; é como abdicar de uma parte de meu ser. Estou certo de que milhares de violonistas sentem o mesmo. Não importa; aquele cuja arte está esculpida na consciência de tantas pessoas nunca morre. Enquanto houver apreço por uma cultura que floresce em sua forma mais exaltada, haverá espaço para se ouvir Julian Bream. 


\section{SOBRE O AUTOR}

Violonista, regente, comunicador e escritor com 30 anos de carreira internacional, autor de discos e livros premiados, professor-visitante da Royal Academy of Music (Londres/ENG) e único brasileiro vencedor dos dois mais importantes concursos internacionais de violão da atualidade: Francisco Tárrega (Espanha) e GFA (EUA). É coordenador artístico e pedagógico do Festival Internacional de Campos do Jordão desde 2013. E-mail: $\underline{\text { fanonogmail.com }}$ 